This item was submitted to Loughborough's Research Repository by the author.

Items in Figshare are protected by copyright, with all rights reserved, unless otherwise indicated.

\title{
Determination of electrical parameters of PMSM drive system at standstill
}

PLEASE CITE THE PUBLISHED VERSION

http://dx.doi.org/10.1109/VPPC.2016.7791663

PUBLISHER

(c) IEEE

VERSION

AM (Accepted Manuscript)

LICENCE

CC BY-NC-ND 4.0

REPOSITORY RECORD

Liu, Kan, and Zi-Qiang Zhu. 2019. "Determination of Electrical Parameters of PMSM Drive System at Standstill”. figshare. https://hdl.handle.net/2134/25345. 


\title{
Determination of Electrical Parameters of PMSM Drive System at Standstill
}

\author{
Kan Liu, Z.Q. Zhu \\ Department of Electronic and Electrical Engineering \\ University of Sheffield \\ Sheffield, U.K. \\ Kan.liu@sheffield.ac.uk, z.q.zhu@sheffield.ac.uk
}

\begin{abstract}
This paper proposes a standstill test method for the determination of electrical parameters of permanent magnet synchronous machine (PMSM) drive system fed by a conventional three-leg inverter. In order to estimate the equivalent total circuit resistance, a self-cancellation method is proposed to eliminate the influence of inverter nonlinearity on the calculation. With the identified equivalent total circuit resistance, the voltage drop due to the inverter nonlinearity can be calculated afterwards. In addition, a method to derive the $d q$ axis inductances from high frequency zero mean $\boldsymbol{d q}$-axis currents is proposed, which does not need the aid of any complex parameter identification algorithm. The proposed method is finally evaluated on a PMSM experimentally and shows quite good performances in the determination of electrical parameters of drive system.
\end{abstract}

Keywords-Electrical machine drive, inverter nonlinearity, parameter determination, permanent magnet synchronous machine, standstill test

\section{INTRODUCTION}

Permanent magnet synchronous machines (PMSMs) become one of the most widely used electrical machines for many applications. Compared with the conventional induction machine, the PMSM has superior performances in terms of higher torque density, lower copper loss and higher efficiency etc. In order to design a high performance PMSM drive controller, the accurate model of machine drive system is needed and should be identified prior to the controller design [1], [2]. For example, electrical parameters such as $d q$-axis inductances and winding resistance of PMSMs are usually needed for the design of current loop proportional- integral (PI) controllers [1], [2]. Besides, since the whole machine drive system is usually fed by the power electronic devices such as the voltage source inverter (VSI), the modeling of the whole drive system also needs to take into account the identification of the contribution of power devices, for example, the voltage drop due to the inverter nonlinearity [3]-[7].

In this paper, a method for the determination of equivalent total circuit resistance and voltage drop due to inverter nonlinearity is proposed, which is based on a self-cancellation in $\alpha \beta$-axis reference frame. From the modeling and related analysis, it is found that for $\alpha$-and $\beta$-axis reference voltages, there are six modes of inverter nonlinearity in one electrical period. Most importantly, in $\beta$-axis reference voltage, the voltage drop due to inverter nonlinearity will be zero in two modes. Thus, at standstill of $i_{d} \neq 0$ and $i_{q}=0$, the equivalent total circuit resistance of PMSM drive system can be directly calculated during the two modes, thanks to the zero contribution of inverter nonlinearity in the $\beta$-axis voltage equation. Afterwards, the voltage drop due to inverter nonlinearity can be obtained by the substitution of identified equivalent total circuit resistance back to the voltage equation.

Besides, the standstill test to derive the $d q$-axis inductances by addition of high frequency zero mean $d q$-axis currents is originally proposed in [4], which needs to use the recursive least square (RLS) algorithm. Based on the same principle, an even simpler method is proposed in this paper, which can derive the $d q$-axis inductances by using only three points of high frequency perturbation signals. The proposed method is finally tested on a prototype PMSM and quite good performances are achieved during the experimental tests.

\section{MODELING OF PMSM AND INVERTER NONLINEARITY}

\section{A. PMSM Voltage Equation}

First, The $d q$-axis PMSM voltage equations taking into account the VSI nonlinearity can be expressed as [5]:

$$
\begin{aligned}
& u_{d}=u_{d}{ }^{*}+D d V_{\text {dead }}=R i_{d}-L_{q} \omega i_{q}+L_{d} \frac{d i_{d}}{d t} \\
& u_{q}=u_{q}{ }^{*}+D q V_{\text {dead }}=R i_{q}+L_{d} \omega i_{d}+L_{q} \frac{d i_{q}}{d t}+\psi_{m} \omega
\end{aligned}
$$

where $u_{d}, u_{q}, u_{d}{ }^{*}, u_{q}{ }^{*}, i_{d}, i_{q}, \omega, L_{d}, L_{q}, R$ and $\psi_{m}$ are the $d q$ axis real and reference voltages, currents, electrical angular speed, $d q$-axis inductances, equivalent total circuit resistance and rotor PM flux linkage, respectively. The equivalent total circuit resistance can be expressed as:

$R=R_{a}+r_{c}+r_{c e}$

where $R_{a}, r_{c}$ and $r_{c e}$ are the stator winding resistance, core loss resistance and loss resistance of power electronic devices. It should be emphasized that the core loss resistance is related to 
the $\mathrm{AC}$ frequency, which can be regarded as zero if there is no AC excitation [8], [9]. Besides, the loss resistance $r_{c e}$ is a lumped resistance representing the influence of on-state resistance and dynamic/steady state loss of IGBT and flyback diode, respectively [3], [10], [11]. In reality, the stator winding resistance will be dominant in (2) while other terms may be different with respect to varying working point. Thus, an approximate determination of equivalent total circuit resistance will be preferred.

In addition, the term $V_{\text {dead }}$ is the distorted voltage due to inverter nonlinearity, which includes the influence of switch on/off time delay $\left.\left(T_{o n}, T_{o f f}\right)\right)$, dead time $\left(T_{d}\right)$, on-state voltage drops due to IGBT $\left(V_{c e 0}\right)$ and diode $\left(V_{d 0}\right)$ and can be expressed as [3]-[5]:

$V_{\text {dead }}=\frac{1}{6}\left(\frac{T_{o f f}-T_{o n}-T_{d}}{T_{s}} V_{d c}-V_{c e 0}-V_{d 0}\right)$

$D_{d}$ and $D_{q}$ can be expressed as [4], [5]:

$$
\begin{gathered}
{\left[\begin{array}{l}
D_{d} \\
D_{q}
\end{array}\right]=2\left[\begin{array}{ccc}
\cos (\theta) & \cos \left(\theta-\frac{2 \pi}{3}\right) & \cos \left(\theta+\frac{2 \pi}{3}\right) \\
-\sin (\theta) & -\sin \left(\theta-\frac{2 \pi}{3}\right) & \sin \left(\theta-\frac{\pi}{3}\right)
\end{array}\right]\left[\begin{array}{l}
\operatorname{sign}\left(i_{a s}\right) \\
\operatorname{sign}\left(i_{b s}\right) \\
\operatorname{sign}\left(i_{c s}\right)
\end{array}\right]} \\
\operatorname{sign}(i)=\left\{\begin{array}{l}
1, i>=0 \\
-1, i<0
\end{array}\right.
\end{gathered}
$$

At steady state of $i_{d}=0$ control, (1) can be simplified to:

$$
\begin{aligned}
& u_{d}=u_{d}{ }^{*}+D d V_{\text {dead }}=R i_{d}-L_{q} \omega i_{q} \\
& u_{q}=u_{q}{ }^{*}+D q V_{\text {dead }}=R i_{q}+\psi_{m} \omega
\end{aligned}
$$

In reality, due to the high frequency PWM, it is usually difficult to measure the terminal voltages of electrical machine. Thus, the reference voltages such as $u_{d}{ }^{*}$ and $u_{q}{ }^{*}$ are always employed for algorithm calculation. In this case, the influence of $V_{\text {dead }}$ should be considered and well compensated to ensure the accuracy.

\section{B. Analysis of Inverter Nonlinearity}

The distorted voltage due to VSI nonlinearity under $\alpha \beta$ reference frame can be derived as follows:

$$
\begin{gathered}
{\left[\begin{array}{c}
V_{a s}^{\prime} \\
V_{b s}^{\prime} \\
V_{c s}^{\prime}
\end{array}\right]=V_{\text {dead }}\left[\begin{array}{ccc}
2 & -1 & -1 \\
-1 & 2 & -1 \\
-1 & -1 & 2
\end{array}\right]\left[\begin{array}{l}
\operatorname{sign}\left(i_{a s}\right) \\
\operatorname{sign}\left(i_{b s}\right) \\
\operatorname{sign}\left(i_{c s}\right)
\end{array}\right]} \\
=V_{\text {dead }} D=V_{\text {dead }}\left[\begin{array}{c}
D_{a} \\
D_{b} \\
D_{c}
\end{array}\right]
\end{gathered}
$$

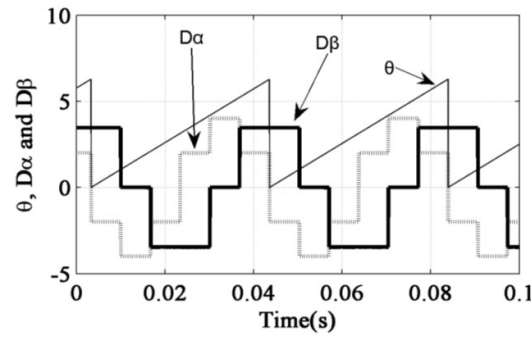

(c)

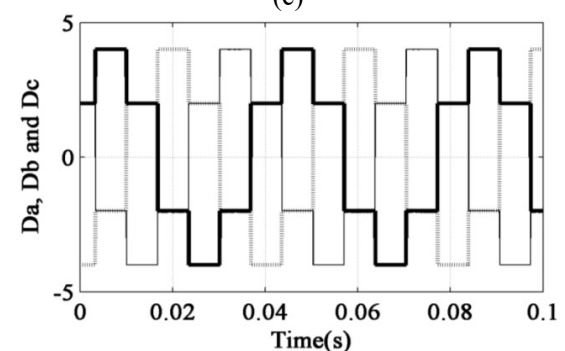

(d)

Fig. 1. Waveform of simulation. (a) $D_{\alpha}$ and $D_{\beta}$ with respect to electrical angular position $(\theta)$. (b) $D_{a}, D_{b}$, and $D_{c}$.

TABLE I

Relationship Between abC ThreE Phase CuRRENTS AND Distorted VOLTAGE DUE TO VSI NONLINEARITY

\begin{tabular}{crrrcc}
\hline Mode & $\operatorname{sign}\left(i_{a s}\right)$ & $\operatorname{sign}\left(i_{c s}\right)$ & $\operatorname{sign}\left(i_{b s}\right)$ & $D_{\alpha}$ & $D_{\beta}$ \\
\hline 1 & 1 & -1 & -1 & 4 & 0 \\
2 & 1 & 1 & -1 & 2 & $2 \sqrt{3}$ \\
3 & -1 & 1 & -1 & -2 & $2 \sqrt{3}$ \\
4 & -1 & 1 & 1 & -4 & 0 \\
5 & -1 & -1 & 1 & -2 & $-2 \sqrt{3}$ \\
6 & 1 & -1 & 1 & 2 & $-2 \sqrt{3}$
\end{tabular}

Transforming (7) into $\alpha \beta$ reference frame it becomes:

$$
\begin{gathered}
\frac{2}{3}\left[\begin{array}{ccc}
1 & -\frac{1}{2} & -\frac{1}{2} \\
0 & \frac{\sqrt{3}}{2} & -\frac{\sqrt{3}}{2}
\end{array}\right]\left[\begin{array}{l}
V_{a s}^{\prime} \\
V_{b s}^{\prime} \\
V_{c s}^{\prime}
\end{array}\right] \\
=V_{\text {dead }}\left[\begin{array}{rrr}
2 & -1 & -1 \\
0 & \sqrt{3} & \sqrt{3}
\end{array}\right]\left[\begin{array}{l}
\operatorname{sign}\left(i_{a s}\right) \\
\operatorname{sign}\left(i_{b s}\right) \\
\operatorname{sign}\left(i_{c s}\right)
\end{array}\right]=V_{\text {dead }}\left[\begin{array}{l}
D_{\alpha} \\
D_{\beta}
\end{array}\right]
\end{gathered}
$$

Thus, as can be seen from Table I, the directions of three phase currents can be expressed in six modes and the simulated waveform of $D_{\alpha}$ and $D_{\beta}$ with respect to electrical angular position $\theta$ is shown in Fig. 1(a). It is noteworthy that $D_{\beta}$ is zero at mode 1 and mode 4 . Thus, in reality, the influence of VSI nonlinearity on $\beta$-axis voltage will be cancelled in mode 1 and mode 4 . However, as can be seen from Fig. 1(b), $D_{a}, D_{b}$, and $D_{c}$ do not have this feature on abc three phase reference frame. Fig. 2(a) shows the investigated prototype PMSM and Fig. 2 (b) shows the measured $D_{\alpha}$ and $D_{\beta}$. It is noteworthy that the waveform of $D_{\beta}$ coincides with Table I that it will be equal to 0 at mode 1 or 4 . In this case, the equivalent total resistance of PMSM at standstill can be estimated from $\beta$-axis equation without influence from VSI nonlinearity at modes 1 or 4 : 


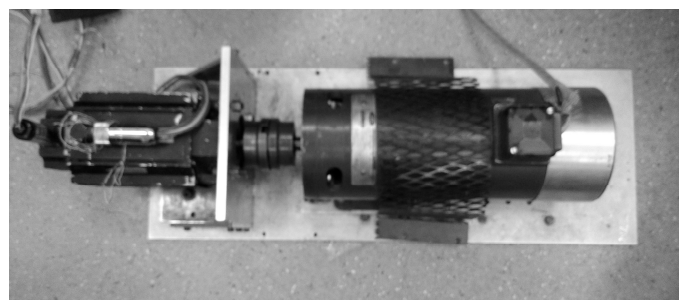

(a)

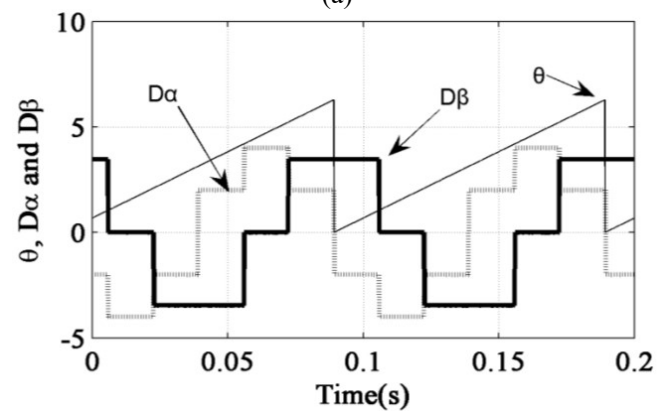

(b)

Fig. 2. Prototype PMSM and waveform of $D_{\alpha}$ and $D_{\beta}$. (a) Tested PMSM and load DC machine. (b) Measured $D_{\alpha}$ and $D_{\beta}$ with respect to electrical angular position $(\theta)$.

$\operatorname{mean}\left(R i_{\beta}\right)=\operatorname{mean}\left(u_{\beta}^{*}(\operatorname{Mode}=1,4)\right)=\operatorname{mean}\left(u_{\beta}\right)$

where 'mean' is the mean operator. Afterwards, the distorted voltage term $V_{\text {dead }}$ can be calculated at Mode $=2,3,5,6$ by:

$$
V_{\text {dead }}=\operatorname{mean}\left(\frac{R i_{\beta}-u_{\beta}^{*}(\text { Mode }=2,3,5,6)}{D_{\beta}}\right)
$$

\section{Determination of Dq-axis Inductances}

At standstill, the rotor PM flux linkage term is eliminated from the machine model, by which the number of unknown parameters is reduced. The simplified PMSM voltage equations can be simplified as:

$u_{d}^{*}(k)=R i_{d}+L_{d} \frac{d i_{d}}{d t}-D d(k) V_{\text {dead }}$

$u_{q}^{*}(k)=R i_{q}+L_{q} \frac{d i_{q}}{d t}-D q(k) V_{\text {dead }}$

As reported in [6], a set of zero mean high frequency $d q$ axis currents, being of small amplitude, can be added into the PMSM at standstill for the calculation of $d q$-axis inductances. Since the rotor speed will be almost zero due to the high frequency zero-mean $q$-axis current, the locking of rotor will not be needed and the $d q$-axis inductances can be calculated afterwards. Assuming that $i_{d p}{ }^{*}$ and $i_{q p}{ }^{*}$ are peak value of added high frequency $d q$-axis perturbations, the $d q$-axis currents can be expressed as $i_{d}=i_{d p}{ }^{*} \sin \left(\omega_{h} t\right)$ and $i_{q}=i_{q p}{ }^{*} \sin \left(\omega_{h} t\right)$. Thus, (11) can be transformed as:

$$
\begin{aligned}
& u_{d}{ }^{*}=R i_{d}^{*} \sin \left(\omega_{h} t\right)+L_{d} i_{d p}^{*} \omega_{h} \cos \left(\omega_{h} t\right)-D d V_{\text {dead }} \\
& u_{q}{ }^{*}=R i_{q}^{*} \sin \left(\omega_{h} t\right)+L_{q} i_{q p}^{*} \omega_{h} \cos \left(\omega_{h} t\right)-D q V_{\text {dead }}
\end{aligned}
$$

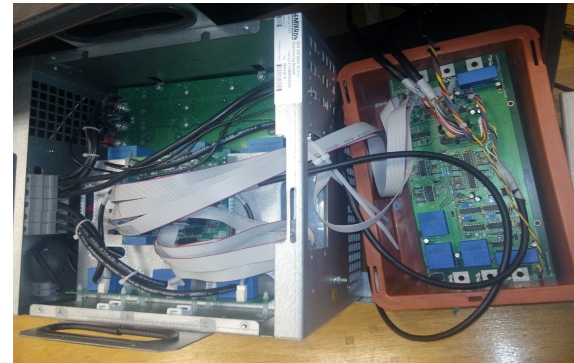

Fig. 3. Semikron SEMIX stack with SEMIX71GD12E4S IGBT modules.

TABLE II

TYPICAL ELECTRICAL PARAMETERS OF VSI (FROM SEMIX71GD12E4S DATASHEET)

\begin{tabular}{lr}
\hline Turn on delay $T_{\text {on }}$ & $0.160 \mu \mathrm{s}$ \\
Turn on/off delay $T_{o f f}$ & $0.433 \mu \mathrm{s}$ \\
Hardware dead time & $4 \mu \mathrm{s}$ \\
Switch control dead time $t_{d}$ & $2 \mu \mathrm{s}$ \\
Voltage drop of the active switch $\left(25^{\circ} \mathrm{C}\right) V_{c e}$ & $1.85 \mathrm{~V}$ \\
Voltage drop of the freewheeling $\operatorname{diode}\left(25^{\circ} \mathrm{C}\right) V_{d}$ & $2.2 \mathrm{~V}$ \\
Supply voltage range & $0-650 \mathrm{~V}$ \\
\hline
\end{tabular}

At the time point of $\omega_{h} t=2 k \pi, k=0,1,2 \ldots$, (12) can be further simplified as:

$u_{d}{ }^{*}\left(\omega_{h} t=2 k \pi\right)=L_{d} i_{d p}^{*} \omega_{h}-D d V_{\text {dead }}$
$u_{q}{ }^{*}\left(\omega_{h} t=2 k \pi\right)=L_{q} i_{q p}^{*} \omega_{h}-D q V_{\text {dead }}$

Thus, the $d q$-axis inductances can be obtained by:

$$
\begin{aligned}
& L_{d}=\frac{u_{d}{ }^{*}\left(\omega_{h} t=2 k \pi\right)+D d V_{\text {dead }}}{\omega_{h} i_{d p}^{*}} \\
& L_{q}=\frac{u_{q}^{*}\left(\omega_{h} t=2 k \pi\right)+D q V_{\text {dead }}}{\omega_{h} i_{q p}^{*}}
\end{aligned}
$$

As can be seen from (14), only three points are needed for the calculation of each of $d q$-axis inductances, which are the real peak value of $i_{d}$ (or $i_{q}$ ), the zero crossing time point $\left(t=t_{0}\right)$ of $i_{d}\left(\right.$ or $\left.i_{q}\right)$, and $u_{d}\left(t=t_{0}\right)$ (or $u_{q}\left(t=t_{0}\right)$ ).

The performance of the above proposed method is then evaluated on the prototype PMSM, whose nominal parameter values are listed in Appendix A for comparison.

\section{EXPERIMENTAL VALIDATION}

The prototype interior PMSM is fed by a Semikron SEMIX stack with SEMIX71GD12E4S IGBT modules, as shown in Fig. 3, of which the main parameter values obtained from datasheet are shown in Table II.

\section{A. Standstill Tests for $R$ and $V_{\text {dead }}$}

The performance of proposed method is firstly tested on the condition that the DC bus voltage is set to $V_{d c}=20 \mathrm{~V}$, as shown in Fig. 4. In order to ensure that $i_{\beta} \neq 0$ and the zero speed of rotor, a small amplitude of flux weakening current $i_{d}=-1 \mathrm{~A}$ is injected. The rotor position of PMSM is set to different values by position control or rotate manually. 


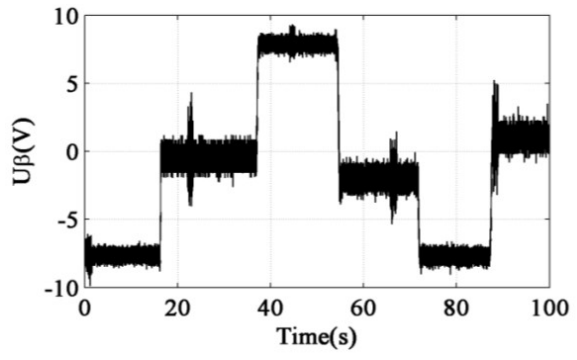

(a)

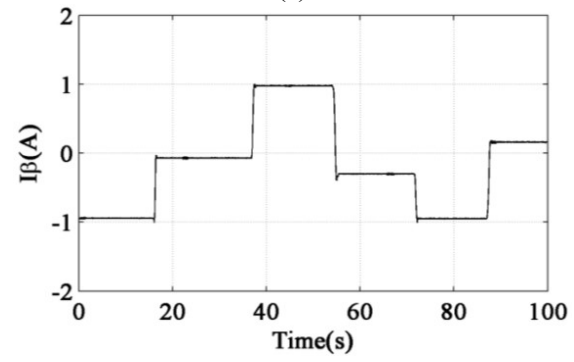

(b)

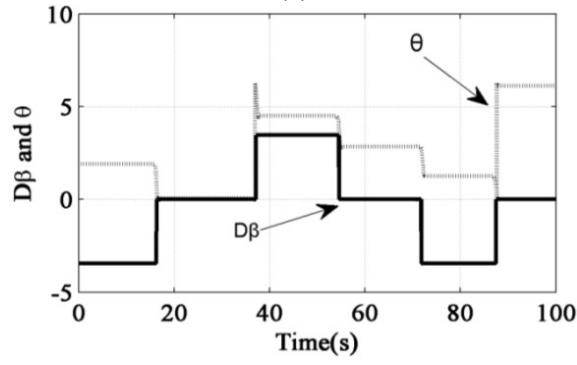

(c)

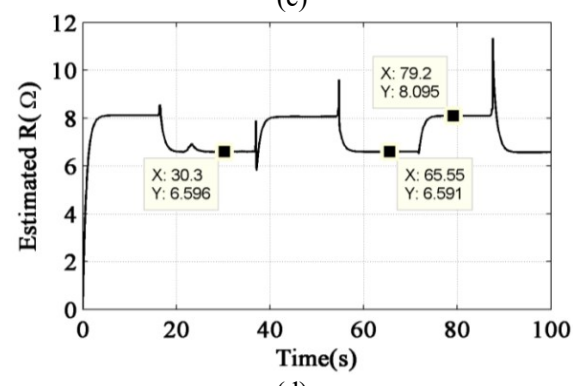

(d)

Fig. 4. Estimation of winding resistance at different rotor positions $\left(V_{d c}=20 \mathrm{~V}\right.$, $i_{d}=-1 \mathrm{~A}$ ). (a) $\beta$-axis voltage. (b) $\beta$-axis current. (c) $D_{\beta}$ and $\theta$. (d) Estimated $R$.

Figs. 4(a) and (b) are the real time measured $\beta$-axis voltage and current for the calculation of equivalent total circuit resistance. As shown in Figs. 4(c) and (d), it is obvious that the calculated equivalent total circuit resistance changes a lot at different rotor positions. It is also obvious that the calculated equivalent total circuit resistance (about $6.6 \Omega$ in average) is quite close to the stator winding resistance $(6.0+0.2=6.2 \Omega)$ at $D_{\beta}=0$, which confirms the previous analysis that the influence of inverter nonlinearity will be cancelled at two modes of $D_{\beta}$. Since there is no AC excitation, the contribution of core loss resistance can be regarded as 0 and the difference $(6.6-6.2=0.4 \Omega)$ can be regarded as the contribution of loss resistance of power electronic devices. With the aid of identified equivalent total circuit resistance, the distorted voltage term due to inverter nonlinearity can be obtained by (10), which is about $V_{\text {dead }}=0.41 \mathrm{~V}$.

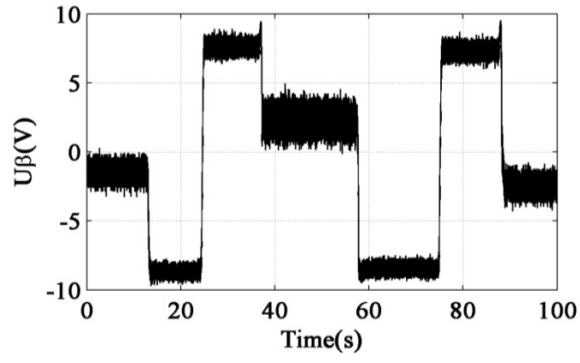

(a)

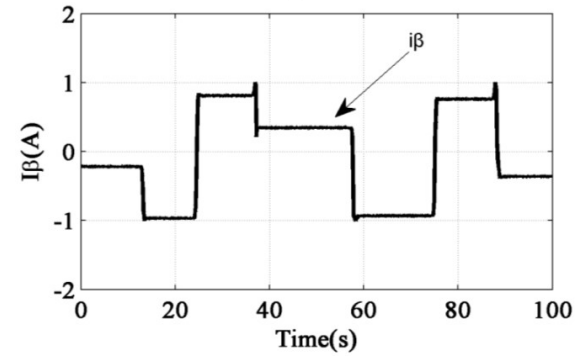

(b)

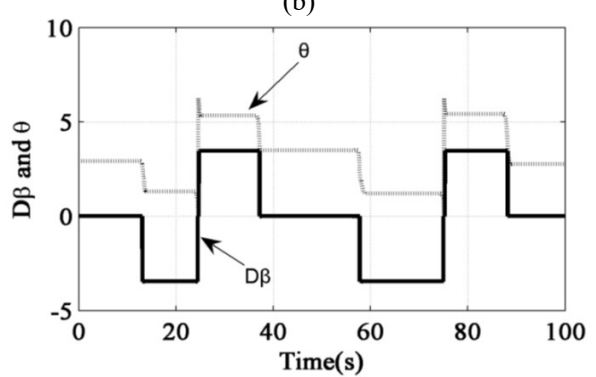

(c)

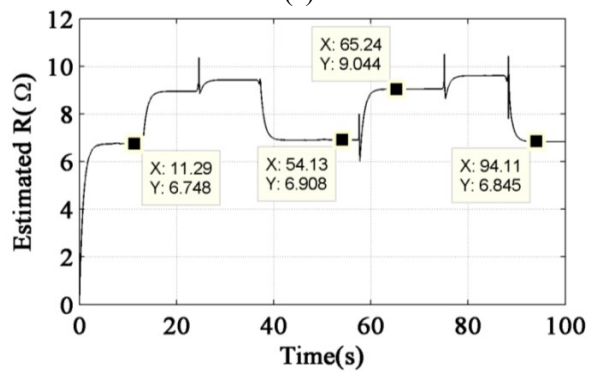

(d)

Fig. 5. Estimation of winding resistance at different rotor positions $\left(V_{d c}=40 \mathrm{~V}\right.$, $i_{d}=-1 \mathrm{~A}$ ). (a) $\beta$-axis voltage. (b) $\beta$-axis current. (c) $D_{\beta}$ and $\theta$. (d) Estimated $R$.

Besides, the influence of DC bus voltage is also investigated and by way of example, it is set to $V_{d c}=40 \mathrm{~V}$, as shown in Fig. 5. It is interesting that the calculated equivalent total circuit resistance (about $6.8 \Omega$ in average) is also close to the stator winding resistance at $D_{\beta}=0$. The rise in the calculated equivalent total circuit resistance $(6.8-6.6=0.2 \Omega)$ can be explained that the dynamic loss in power device is increased due to the rise of DC bus voltage [10]. Similarly, the voltage term due to inverter nonlinearity can be obtained by (10) and is about $V_{\text {dead }}=0.62 \mathrm{~V}$.

\section{B. Determination of Dq-axis inductances}

Fig. 6 shows the measured high frequency zero mean $d q$ axis currents and voltages for the determination of $d q$-axis inductances, in which the DC bus voltage is set to $V_{d c}=40 \mathrm{~V}$. 


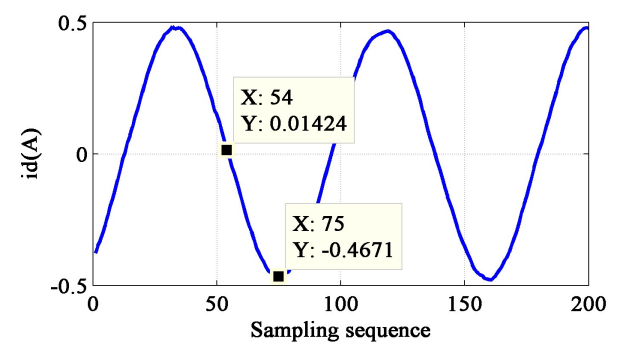

(a)

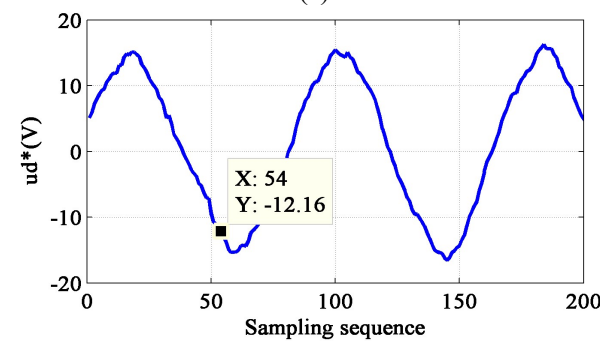

(b)
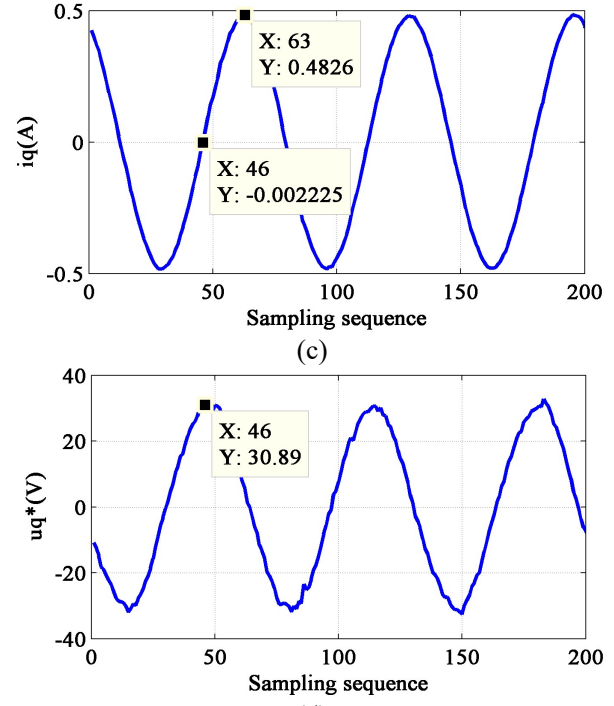

(d)

Fig. 6. $D q$-axis high frequency zero mean signals. (a) and (b) Measured $d$-axis current and reference voltage, $i_{d}=i_{d p}{ }^{*} \sin \left(\omega_{h} t\right), \omega_{h}=120 \mathrm{~Hz}$. (c) and (d) Measured $q$-axis current and reference voltage, $i_{q}=i_{q p}{ }^{*} \sin \left(\omega_{h} t\right), \omega_{h}=150 \mathrm{~Hz}$.

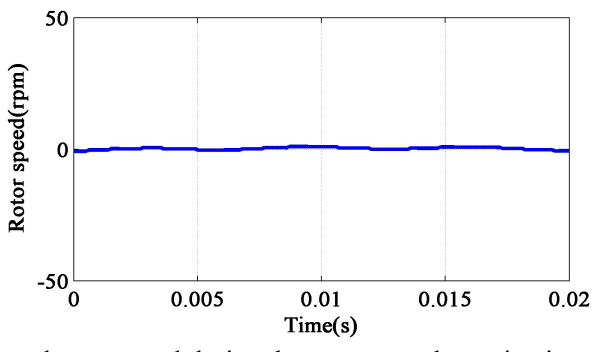

Fig. 7. Measured rotor speed during the parameter determination.

In order to ensure the zero rotor speed, the frequency of zero mean $i_{q}$ is set to $150 \mathrm{~Hz}$ while the frequency of zero mean $i_{d}$ is set to $120 \mathrm{~Hz}$. The reason why the frequency of $i_{q}$ is higher is that $i_{q}$ is dominant in the generation of electromagnetic torque. Since the frequency of injected $d q$-axis currents is relatively high and the time constant of mechanical part is relatively large, the rotor speed will be almost zero during the test, as shown in Fig. 7. As mentioned in section II C, three points of measured data are needed for the determination of $d$ or $q$-axis inductance, which can be achieved by using the code introduced in Appendix B. The obtained useful points are shown in Fig. 6, by which the $d q$-axis inductances can be derived as follows:

$$
\begin{aligned}
& L_{d}=\frac{u_{d}{ }^{*}\left(\omega_{h} t=2 k \pi\right)+D d V_{\text {dead }}}{\omega_{h} i_{d p}^{*}} \\
& =\frac{-12.16+D d V_{\text {dead }}}{-120 \times 2 \times \pi \times 0.4671} \approx 0.0324 \mathrm{H}=32.4 \mathrm{mH} \\
& L_{q}=\frac{u_{q}^{*}\left(\omega_{h} t=2 k \pi\right)+D q V_{\text {dead }}}{\omega_{h} i_{q p}^{*}}=\frac{30.89+D q V_{\text {dead }}}{-150 \times 2 \times \pi \times 0.4826}
\end{aligned}
$$

$\approx 0.0663 \mathrm{H}=66.3 \mathrm{mH}$

where $V_{\text {dead }}=0.62 \mathrm{~V}$ since $V_{d c}=40 \mathrm{~V}$. Compared with the nominal parameter values shown in Table III, the derived $d q$ axis inductances are quite close to their design parameters.

\section{CONCLUSION}

This paper introduces a standstill test for the parameter determination of PMSM drive system. The equivalent total resistance of drive system can be obtained by a selfcancellation process, with the aid of which the distorted voltage due to inverter nonlinearity can be derived afterwards. The $d q$-axis inductances of PMSM can be derived by a proposed method with the aid of addition of high frequency $d q$-axis currents, in which those complex system identification algorithms are not needed and the influence of equivalent total resistance is also eliminated during the design process of algorithm.

\section{APPENDIX A}

The nominal parameter values of prototype PMSM are listed in Table III.

TABLE III

DESIGN PARAMETERS AND SPECIFICATION OF PMSM

\begin{tabular}{ll}
\hline Parameters & Value \\
\hline Rated current & $4 \mathrm{~A}$ \\
Rated speed & $400 \mathrm{rpm}$ \\
DC link voltage & $100 \mathrm{~V}$ \\
Nominal phase resistance & $6.000 \Omega$ \\
Terminal wire resistance & $0.2 \Omega$ \\
Nominal $d$-axis inductances & $38.10 \mathrm{mH}$ \\
Nominal $q$-axis inductances & $58.50 \mathrm{mH}$ \\
Nominal rotor PM flux linkage & $236.0 \mathrm{mWb}$ \\
Number of pole pairs & 3 \\
Number of stator slots & 18 \\
Number of lines of encoder & 2048 \\
\hline Note: Nominal valucs arem
\end{tabular}

Number of lines of encoder

\section{APPENDIX B}

The fake code for zero crossing detection is shown below, in which variables such as Data, Polarity, and ZeroCrossing are measured raw data such as $i_{d}$ (or $i_{q}$ ), polarity of measured data, and sequence number of zero crossing point of measured raw data, respectively. 


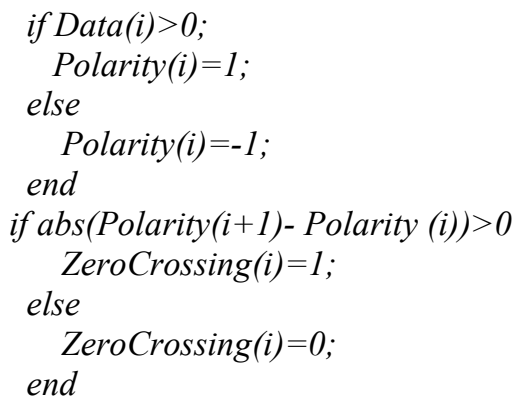

Assuming that $N$ points will be sampled in each cycle of high frequency perturbation, the peak (or valley) value of $i_{d}$ or $i_{q}$ will be at the sampling point of $\operatorname{int}(i+0.25 N)$. The operator ' int' is to get the integer part of data.

\section{REFERENCES}

[1] T. Senjyu, K. Kinjo, N. Urasaki, and K. Uezato, "Parameter measurement for PMSM using adaptive identification," in Proc. IEEE Int. Symp. Ind. Electron., May 2002, vol. 3, pp. 711-716.

[2] K. Liu, and Z.Q. Zhu, "Parameter estimation of PMSM for aiding PI regulator design of field oriented control," in Proc. ICEMS, 2014, pp. 2705-2711.
[3] J.W. Choi, and S.K. Sul, "Inverter output voltage synthesis using novel dead-time compensation," IEEE Trans. Power Electron., vol. 11, no. 2, pp. 221-227, Mar. 1996

[4] H. S. Kim, K. H. Kim, and M. J.Youn, "On-line dead-time compensation method based on time delay control," IEEE Trans. Contr. Syst. Technol., vol. 11, no. 2, pp. 279-285, Mar./Apr. 2003.

[5] H.W. Kim, M.J. Youn, K.Y. Cho, and H.S. Kim, "Nonlinearity estimation and compensation of PWM VSI for PMSM under resistance and flux linkage uncertainty," IEEE Trans. Contr. Syst. Technol., vol. 14, no. 4, pp. 589-601, Jul. 2006.

[6] S. Morimoto, M. Sanada, and Y. Yakeda, "Mechanical sensorless drives of IPMSM with online parameter identification," IEEE Trans. Ind. Applicat., vol. 42, no. 5, pp. 1241-1248, Sept./Oct, 2006.

[7] K. Liu, and Z.Q. Zhu, "Online estimation of rotor flux linkage and voltage source inverter nonlinearity in permanent magnet synchronous machine drives," IEEE Trans. Power Electron., vol. 29, no. 1, pp. 418427, 2014.

[8] T. Senjyu, Y. Kuwae, N. Urasaki and K. Uezato, "Accurate parameter measurement for high speed permanent magnet," in Proc. IEEE Power Electron. Specialists Conf., 2001, vol. 2, pp. 772-777.

[9] I. Lar, and M.M. Radulescu, "Equivalent core-loss resistance identification for interior permanent-magnet synchronous machines," in Proc. IEEE International Conf. Electrical Machines, 2012, vol. 2, pp. 1665-1669.

[10] F. Casanellas, "Losses in PWM inverters using IGBTs," IEE Proc.Electric Power Applicat., vol. 141, no. 5, pp. 235-239, 1994.

[11] L.K. Mestha, P.D. Evans, "Analysis of on-state losses in PWM inverters," IEE Proc. B Electric Power Applicat., vol. 136, no. 4, pp. $189-195,1989$. 